\title{
Comparative Studies on the Butterfly Diversity and Species Richness in Selected Agricultural Fields in Tamil Nadu
}

\author{
Radha R*, Susheela P , Subhashini K \\ *Department of Zoology, Sree Ayyappa College for Women, Nagercoil, Tamilnadu, India \\ Department of Zoology, PSGR Krishnammal College for Women, Coimbatore, Tamilnadu,India
}

\begin{abstract}
Butterflies are valued components of grassland ecosystems both for their aesthetic nature and they provide as pollinators of the ecosystem services. Loss and fragmentation of native habitats, along with other disturbances associated with intensive agriculture can have dramatic effects on butterfly communities. The close link between butterflies and their natural environment make them good candidates for use as ecological indicators. Hence an attempt has been made to study the diversity and pollination tendencies of butterflies between organic crop fields and pesticide sprayed crop fields. The research was set out to establish whether organic and conventional farming systems support different levels of pest and non-pest butterflies. In the present study maximum insect abundance and total number of individuals were recorded in organic fields. The study also proved that organic farming practices can help in the population build-up of natural enemies and pollinators. However there was remarkable difference in Shannon index and Simpson index of diversity between organic and chemical fields. Phytophagous insect populations were very low in number in organic farms. Hence organic farming practices may encourage natural enemies' diversity and may not be favourable for pests.
\end{abstract}

Keywords-Butterflies, Organic Field, Conventional Field, Shannon Index, Simpson Index.

\section{INTRODUCTION}

Plants and animals on the planet earth have a close interdependent relationship which is the basic factor around which their survival and propagation depends on. Especially the insects that feed on the secretions of the flowers are vital in the spread of that particular plant species as these insects carry pollens and aid in pollination. Flower visiting insects provide important ecosystem services like pollination and pest control. The importance of landscape context for the species richness of flower visiting insects depends upon the quality of the habitat patches (Bandry et al., 2000).
Pollinators are critical for the reproduction of many plants, and about $94 \%$ of plant species in tropical communities and third of global food crops are likely to rely on animal pollination (Arun et al. 2003; Caldas et al.2003).Pollination is one of the most important types of interaction between plants and animals in ecosystems because it is a key process in the sexual reproduction of most angiosperms and can affect directly the plant reproduction success( Arun,2002). The process of transportation of pollens fromstamens to the ovary is called pollination. A great majority of flowers that we see around us today are insect pollinated or entomophilous. Flowers can attract pollinators by providing ample nectar of the right composition, and by advertising this nectar by deep shape and recognizable floral patterns, by providing excess pollen as food, or by providing shelter or a place to raise young (Bengtsson et $a l ; 2005)$. It is generally only adult winged insects that specialize in visiting flowers.

Butterflies are the most beautiful and colorful creatures on the earth and have a great aesthetic value. Butterflies (Lepidoptera) are very important group of plants and insects (Family, species level analysis) and to insects because they take part in the key stone ecological access the relationship between insects and plants based process of pollination (Culliney et al., 1986). There are about 18,000 species based on colour and size of the flower. India has 1,501 species, of which 321 are Skippers, 107 Swallowtails, and 109 Whites. Somebutterflies are migratory and they fly thousands of milesin the winter to places having a warmer climate, andreturn back in the spring. Butterflies serve asimportant plant pollinators in the local environment,and help to pollinate more than 50 economicallyimportant plant crops (Feber et al., 1997). Butterfliesare also good indicators of environmental changes asthey are sensitive to habitat degradation and climate changes (Kunte,2008). Flowers pollinated by butterflies secrete sucrose-rich nectar (Crowder; et al. 2010; Gabriel; et al. 2010). Inaddition to the floral reward, in terms of number of flowersdisplayed or open, flower attractiveness may have a positiveinfluence on the 
abundance and frequency of the flower visitors (Rickets, 2001; Isart;et al. 2003). In addition, weather and light conditions influence the flower visitors' behaviour. Studies by Pollard (1977),Larsen(1987) and Rosin et al. (2012) revealed impacts of temperature, solarradiation and time of day on the number of floral visitors andtheir frequency.

Butterflies are valued components of grassland ecosystems both for their aesthetic nature and because of the ecosystem services they provide as pollinators (Rundlof et al; 1991). Loss and fragmentation of native habitats, along with other disturbances associated with intensive agriculture can have dramatic effects on butterfly communities. The close link between butterflies and their natural environment make them good candidates for use as ecological indicators (Saikia, et al; 2009). In addition, the habitat requirements and life histories of most butterfly species are well known, allowing for easier interpretation of population characteristics. There is virtually has not been anypublished research works on agricultural butterfliesecology in India whereas, it is essential to have such dataso far as the understanding of the butterfly biodiversityand conservation in agro ecosystem is concerned.

Butterflies being important pollinating agents for wild and crop plants around the world, it has become useful to conserve those beneficial insects (Sreekumar et al; 2001). It is required to make extensive studies on their foraging behaviours and the decline in the butterfly species in agricultural landscape.(Stopes et al., 1995). It is very clear that agricultural fields are containing several agrestals (Thomas et al, 1992) with main crop which are attracted by butterflies for their various purposes. In the West Bengal of India severalworks on butterflies done at Kolkata or its eastern part and North Bengal (Mathew et al; 2007; Jahanban et al; 2012) but little work done in the district Coimbatore ofTamilnadu (Soubaddra et al;2001). So, it is necessary to study about thebutterflies' diversity of this district especially agriculturalfields which decrease rapidly due to industrialization process which is increase day by day and urbanization of the district.

Agricultural intensification is widely accepted as a cause ofbiodiversity decline. It is however a broad conceptencompassing many factors, such as the loss of semi-naturalhabitat, fragmentation of ecosystem, use of heavy machineryand increased input of insecticides, pesticides and herbicides(Kristeiansen et al., 2006). Of these, chemical pesticides potentiallyaffect development of butterfly larva and nectar producingplants which adversely affect adult butterfly diversity. Adulttemperate butterflies feed primarily on nectar (Mathew et al; 2002), supplemented to varying extents by mud, dung or carrion (Larsen, 1987). Developments of agriculture field in forestecosystem endanger many species throughout the world; atpresent extinction rates are estimated to be 100 to 1,000 timesthe natural rates, depending on the taxonomic group.

The use of pesticides (particularly herbicides) and synthetic fertilisers has increased dramatically over the past 60 years. In industrialised countries, farming practices have fundamentally changed. Over the past 40 years, the use of highly toxic carbamate and organophosphate has strongly increased. In the south, organochlorines such as endosulfan, highly persistent in the environment, are still used on a large scale. With habitat change, pesticide poisoning can cause major population decline which may threaten rare species (Letourneau etal;2008).Agricultural pesticides can reduce the abundance of weeds and insects which are important food sources for many species(Pollard et al;1975). Herbicides can change habitats by altering vegetation structure, ultimately leading to population decline.

Organic farming is a method of farming system which primarily aims at raising crops using organic wastes and other biological materials along with beneficial microbes for increased sustainable production without spoiling the soil health. For thousands of years farmers are using organic wastes as fertilizers. Organic wastes do not spoil the soil health and soil microorganisms. United States Department of Agriculture (USDA) study team defines organic farming as 'a system which avoids or largely excludes the use of synthetic inputs (such as fertilizers, pesticides, hormones, feed additives, etc.) and to the maximum extent feasible rely upon crop rotations, crop residues, animal manures, off-farm organic waste, mineral grade rock additives and biological system of nutrient mobilization and plant protection' (Lampkin et al., 2012). Food and Agricultural Organization states: (FAO) 'Organic agriculture is a unique production management system which promotes and enhances agro-ecosystem health, including biodiversity, biological cycles and soil biological activity, and this is accomplished by using onfarm agronomic, biological and mechanical methods in exclusion of all synthetic off-farm inputs' (Maeder et al, 2002)

Hence an attempt has been made to study the diversity and pollination tendencies of butterflies between organic crop fields and pesticide sprayed crop fields. The research was set out to establish whether organic and conventional farming systems support different levels of pest and nonpest butterflies. The study was also aimed to examine the diversity, dominance and evenness of butterflies across the conventional field and organic field located in different altitudes from the southern part of Western Ghats and to correlate with the anthropological activity, 
availability of host plant and the deleterious effect of pesticide in the fields.

\section{MATERIALS AND METHODS}

\subsection{Study area}

The study was conducted in two different villages in Coimbatore District, Tamil Nadu. The organic farm was maintained in Aalandurai, Coimbatore. In organic farm, the farmer applied only organic fertilizers like farm yard manure, vermicompost and biofertilizers. The farmer was continuously following organic farming practices for the previous ten years in the same field. Botanical pesticides such as neem-based commercial formulations and crude extracts of neem seed kernel and leaves of Neem, Calotropis and Vitex were used as pesticides. 'Panchakavya; a natural formulation was used as plant growth promotor as well as pesticide.

The conventional field, in which chemical fertilizers and chemical pesticides were applied, was located in Bomannampalayam, Coimbatore. In this farm, the farmer followed chemical method of pest control and crop management. Synthetic fertilizers like Urea and diammonium phosphate were applied in the farm. The field is a one acre land surrounded by adjacent crop fields. The field is well away from human habitation with less human and animal interaction. In each organic and conventional field, oneacre field area was selected for insect sampling.

\subsection{Observation of foraging behaviour of butterflies}

A study was conducted regarding crop plants visited by butterflies, their foraging activity and abundance at different locations. The key characters used for identification were colour pattern, wing span, mode of flight etc. during thestudy, flight patterns, activity patterns and behaviourswere also noted. Observations were made between 9 a.m.to 5 p.m. These observation were made for a period of 6months from June 2015 to September 2015. All observations were made on clear, warm $\left(20^{\circ}\right.$ $27^{\circ} \mathrm{C}$ )days, when winds were calm. In addition to this the photographic documentation was also used. The insects were identified by using various field guides and other available literatures.

\subsection{Diversity analysis: Monitoring (Line transect)}

Butterfly species density was assessed quantitatively across different fields. Modifications of the line transect count as per. Kunte; (1997) was used to determine butterfly richness and abundance. In this method permanent $50 \mathrm{~m}$ line transect was setup in each habitat. The transect in each habitat was slowly traversed at a uniform pace for $30 \mathrm{~min}$ at each habitats from 16.30 hours to 17.00 hours during good weather period (no heavy rain or strong winds). Butterfly species were recorded around a radius of five meter from the observer covering his either sides, above and front.This is a suitable method for surveying butterflies in a wide range of habitats including tropical forest (Walpole and Sheldon, 1999;Caldas and Robbins, 2003; Koh and Sodhi, 2004). All individuals were identified in the field using standard guides (Sorenson,1948; Senthilkumar,2003; Southwood,1978)

2.3 Shannon-Weiner Index: Species evenness, richness, and diversity indices as Shannon-Weiner (Shannon and Weaver, 1948) and Simpson Index were used to evaluate the butterfly species diversity. Shannon-Weiner Index assumes that individuals are randomly sampled from an independent large population and all the species are represented in the sample. Shannon diversity is very widely used index for comparing diversity between various habitats (Ruszazyk et al;1992)It was calculated in order to know the species diversity in different habitat (Thomas, 1975) based on the abundance of the species by the following formula:

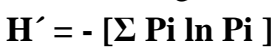

Where, $\mathrm{H}^{\prime}=$ Diversity Index; $\mathrm{Pi}=$ is the proportion of each species in the sample; $\operatorname{lnPi}=$ natural logarithm of this proportion

The presence of one individual of a species is not necessarily indicative of the species being present in a large number. The value of Shannon Weiner Diversity Index usually falls between 1.5 and 3.5 , only rarely it surpasses 4.5 . A value near 4.6 would indicate that the numbers of individuals are evenly distributed between all the species.

2.4 Simpson Index (D): It measures the probability that two individuals randomly selected from a sample will belong to the same species. Simpson gave the probability of any two individuals drawn from noticeably large community belonging to different species. It has been measured by the given formula:

$D=1-\{\Sigma n(n-1) N(N-1)\}$

$\mathrm{n}=$ the total number of butterflies of a particular species $\mathrm{N}=$ the total number of birds of all species

\section{RESULTS AND DISCUSSION}

Table 1 shows the fertilizer/manures/biopesticides/insecticide application in conventional and organic fields. The conventional field used $100-115 \mathrm{~kg} \mathrm{~N}$ (Urea),60-75 $\quad \mathrm{kg} \quad \mathrm{P}_{2} \mathrm{O}_{5}, 35-45 \quad \mathrm{~kg}, \mathrm{~K}_{2} \mathrm{O}(\mathrm{KCl}), 220-230 \quad 1$ insecticides /ha and artificial growth regulators for growing broad bean plant. The organic field used $50 \mathrm{mg}$ Cow dung compost, $13 \mathrm{mg}$ Green manure, $1.5 \mathrm{mg}$ vermicompost,50 1 Panchakavya,60 1 bio-pesticides,neem seed kernel and neem leaf extractsand farm yard manure in the field for growing tomato plants.

The total number of butterfly species observed in conventional field in Bommanampalayam is presented in Table 2.Thaverage temperature recorded in the study area 
was $28^{\circ}$ C.The observation time stared from 16.30 to 17.00 in the evening. A total of 35 butterflies belonging to species Lampides boeticus were found foraging in the conventional field.

The total number of butterfly species observed in organic field in Alandurai is presented in Table3. The average temperature recorded in the study area was $32^{\circ} \mathrm{C}$. The observation time stared from 16.30 to 17.00 in the evening. A total of 61 butterflies belonging to species Castalias rosimon were found foraging in the organic field.

Table 4 shows the percent contribution of relative number of individuals and species of different families of butterflies recorded from the study areas. A total of of 96 butterflies belonging to the family Lycaenidae were recorded during the survey. Out of the 96 species, a maximum of 35 butterflies were recorded in the conventional field.A total of 61 individuals were recorded from the organic field. Out of the families of butterflies, Lycaenidae were the most commonly recorded.

The species richness, abundance and diversity of butterfly fauna sampled in two different fields in Coimbatore are formulated in Table 5.The ecological indices of the conventional field and organic field was calculated. It was found that the Simpson Diversity Index (D) was 0.13 for conventional field and was 0.40 for organic field. The Shannon-Wiener Diversity Index $(\mathrm{H})$ also varied among the two fields. In conventional field, it was -0.16 and for organic field it was -0.12 .

Insects have co-evolved with plants for millions of years and are of enormous importance for agriculture. Some insects can damage crops, but others also provide pollination and pest control services, or improve the fertility of the soil through feeding on and assisting the decomposition of organic matter. Conventional agricultural pest-management practices often lead to altered community structure (Spitzer et al. 1993) and communities dominated by a few species, which contributes to pest outbreaks. Organic farming methods mitigate this ecological damage by promoting evenness among natural enemies (Tiple et al. 2007) which then contributes to a pest-predator balance. Hence, species evenness was considered an important response variable in the present study. While many studies in Europe, Australia and Mexico (Tscharntke et al; 2002) have demonstrated that organic plantations support a greater level of insect diversity, such studies are lacking in tropical zones which harbour similar biodiversity.

Biodiversity in agricultural landscapes is affected by many factors such as farming system, field margins, edge zones, habitat islands, hedgerows, natural pastures, wetlands, ditches, ponds and other small habitats (Tyagi et al., 2011). Biodiversity can be preserved by the restoration and management of small habitats within the agroecosystems (Tiple et al;2009). In recent years organic farming is given much importance due to the consumer demand and concerns about safe food and safe environment (Uniyal et al;1998)

Organic farming is often thought of as a solution to the problems associated with biodiversity conservation in intensive agricultural landscapes. Our study shows that there is greater level of insect diversity on organic fields when compared to the conventional (chemical fertilizers and pesticide-sprayed) fields. Our study supports the contention that organic farming enhances biodiversity. Conventional agricultural pest-management practices often lead to altered food web structure and communities dominated by a few common species, which together contribute to pest outbreaks. Organic farming methods mitigate this ecological damage by promoting evenness among natural enemies (Vandermeer et al; 1995) which then contributes to a pest-predator balance. Hence, species evenness was considered an important response variable in the present study. Our results confirm the hypothesis that organic farming promotes species evenness of butterflies.

In the present study, butterflies populations were more abundant in organic field compared to chemical field. This finding is supported by earlier studies by several ecologists. Youngberg et al (1995) have compared the biodiversity of natural enemies and phytophagous insects between organic and chemical farming systems in the Sacramento Valley. They found that richness was higher (61) in organic samples compared to chemical field samples (35). Feber et al., (1997) have reported that organic farms recorded significantly high total abundance of butterflies than chemical farms and their findings supported the fact that organic farms were favourable to non-pest species. Gabriel et al., (2010) have reported that organic farms supported more insects especially more butterflies compared to chemical farms. Rundlof and Smith (2006) have studied the effect of farming practice on butterfly species richness and abundance on organic and chemical farms in homogeneous and heterogeneous landscape diversity. They found that organic farming and landscape heterogeneity significantly increased butterfly species richness and abundance. Culliney and Pimentel (1986) have reported that phytophagous insect populations were lower in organic farms than chemical fertilizer applied field.

In this study the total number of taxa of butterflies was generally found to be higher in both organic and chemical fields. The data generated and analyzed here clearly show that pesticide treatment has a significant negative effect on insect biodiversity as measured by Shannon's diversity and evenness indices. A comparative effect of treatment 
on mean Shannon's diversity index H' for ground insects within each crop type clearly indicates that organic (and NPK) fields have higher levels of biodiversity than corresponding organic fields.However, pesticide-treated conventional fields show the lowest levels of insect biodiversity. When the two different farming practices were compared, organic field recorded higher number of taxa. So it is not clear whether the farming practice can affect the occurrence of certain species. There was no clear difference in the Evenness between organic and chemical fields. However some workers have documented higher Evenness of natural enemies in organic farms. Crowder et al. (2010) have documented high Evenness of predatory insects in organic farms. The higher activity of natural enemies in organic farming systems can be attributed to the reduced use of broad-spectrum pesticides Pesticides are a major factor affecting biological diversity, along with habitat loss and climate change. They can have toxic effects in the short term in directly exposed organisms, or long-term effects by causing changes in habitat and the food chain. Agricultural pesticides can reduce the abundance of weeds and insects which are important food sources for many species. Herbicides can change habitats by altering vegetation structure, ultimately leading to population decline.

Our study shows that organic field support greater diversity of butterflies, and that butterflies are a good indicator taxon. The number of pesticide applications was seen to have a strong effect on insect diversity (Ramesh $e t$ al; 2010). A better understanding of how species interact within a community and how communities function at the landscape level could be keys to the maintenance and utilization of biodiversity in agri-ecosystems. Therefore, there is a crucial need to conduct further similar research studies, at multiple spatial and temporal scales, especially from tropical regions dominated by agriculture.

\section{CONCLUSION}

In the present study maximum insect abundance and total number of individuals were recorded in organic fields. The study also proved that organic farming practices can help in the population build-up of natural enemies and pollinators. However there was remarkable difference in Shannon index and Simpson index of diversity between organic and chemical fields. Phytophagous insect populations were very low in number in organic farms. Hence organic farming practices may encourage natural enemies' diversity and may not be favourable for pests.

Butterfly diversity of agro-ecosystem of this district is very high but cannot compare with past due to lack of previous data. Agricultural fields are unique ecosystem that provides several services to butterflies. So, different butterflies depend on these fields, but now a day due to urbanization these animals are under risk. Their diversity in the fields also signs of good health of agricultural fields. From this study it can be concluded that health of the fields of this district is fair in respect of butterfly diversity because these insects are very good pollution indicators of whole environment.

The above derived results were analyzed to conclude that organic field using eco-friendly pesticides and fertilizers are definitely the regions with high pollination of the plants in the field. This again is derived from the fact that butterflies get affected by the chemical used in conventional fields which in turn decreases the pollination tendencies of that butterfly population present in that region. The pesticides, or other features of intensive agriculture linked to pesticide use played a major part in the decline of imperilled species.

The results suggest that the management practices associated with farm size are an important factor affecting biodiversity. A positive correlation was found between abundance of butterflies and herbaceous plants, thus supporting the fact that butterfly assessment could be used as an indicator of the lower trophic level species. Thus the current study illustrates how important it is to preserve small-scale agricultural areas in order to avoid further decline in butterfly diversity.

\section{REFERENCES}

[1] Arun P,B, Azeez P,A, On the butterflies of Puyankutty forest, Kerala, India. Zoo's print.J. 18(12): 1276-1279,2003.

[2] Arun P,R, Butterflies of Siruvani forest of Western Ghats, with notes on their seasonality. Zoo's print. J. 18(2): 1003-1006, 2002.

[3] Baudry, J., Burel, F. Thenail, C. and Coeur, L., A holistic landscape ecology study of the interactions between activities and ecological patterns in Brittany, France. Landscape and Urban Planning, 50: 119-128,2000.

[4] Bengtsson, J., Ahnstrom, J. and Weibull, A.C., The effects of organic agriculture on biodiversity and abundance: a meta analysis. J. Appl. Ecol. 42: 261269,2005.

[5] Caldas A, Robbins R,K,Modified Pollard transects for assessing tropical butterfly abundance and diversity. Biol. Conserv. 110: 211-219,2003.

[6] Crowder, D.W. Northfield, D.T. Strand, M.R., and Snyder, W.E, Organic agriculture promotes evenness and natural pest control. Nature, 466(7302):109-12, 2010.

[7] Culliney, T.W. and Pimentel, D, Ecological effects of organic agricultural practices on insect populations. Agric. Ecosys. Environ., 15(4): 253$266,1986$. 
[8] Feber, R.E., Firbank, L.G., Johnson, and P.J., Macdonald, D.W, The effects of organic farming on pest and non-pest butterfly abundance. Agric. EcosyEnviron., 64:133-139,1997.

[9] Gabriel, D.S., M. Sait, J.A. Hodgson, U. Schmutz, W.E. and Kunin, Benton, T.G,Scale matters: the impact of organic farming on biodiversity at different spatial scales. Ecology Letters, 13(7): 858869,2010 .

[10] Isart, J. and Llerena, J.J, Biodiversity and Land Use: The role of Organic Farming. Proceedings of the First ENOF Workshop-Barcelona, pp.155,1996.

[11]Jahanban, L. and Davari, M, Standards and certification procedures in organic agriculture: An overview focusing on organic crop production. Int. Res. J. Appl. Basic Sci., 3 (9): 1825-1836, 2012.

[12] Kristiansen, P, Overview of organic agriculture. In: Organic agriculture: A global perspective (Eds. Kristiansen, P., Taji, A., and Reganold, J.). Collingwood, Australia: CSIRO Publishing, 2006.

[13]Kunte, K, The Wildlife (Protection) Act and conservation prioritization of butterflies of the Western Ghats, southwestern India.Curr. Sci. India 94: 729-735, 2008.

[14]Lampkin, N., Measures, M. and Padel, S, Organic Farm Management Handbook. 9th edition. Organic Research Centre, Newbury,2012.

[15] Larsen T B, The butterflies of the Nilgiri Mountains of Southern India (Lepidoptera: Rhopalocera). BNHS, 84: 291-316, 1987.

[16] Letourneau, D.K. and Bothwell, S.G, Comparison of organic and conventional farms: challenging ecologists to make biodiversity functional. Front.Ecol. Environ., 6(8): 430-438,2008.

[17] Maeder, P., A. Fliebach, and Dubois, D, Soil fertility and biodiversity in organic farming. Sci., 296: 169497, 2002.

[18] Mathew G, Anto M, In situ conservation of butterflies through establishment of butterfly gardens: A case study at Peechi, Kerala,India. Curr. Sci. India, 93(3): 337-347,2007.

[19] Mathew G, Binoy C,F.,Migration of butterflies (Lepidoptera:Rhopalocera) in the new Amarambalam reserve forest of the Nilgiri biosphere reserve. Zoo's Print J. 17(8): 844-847, 2002.

[20]Pollard,E, A method for assessing changes in the abundance of butterflies. Biological Conservation 12 115-131, 1977.

[21]Pollard E, Elias D,O, Skelton M,J and Thomas J,A, A method of assessing the abundance of butterflies in Monks Wood national Nature Reserve in 1973. Entomologist's Gazette 26 79-88, 1975.
[22] Ramesh T, Hussain KJ, Selvanayagam M, Satpathy, $\mathrm{K}, \mathrm{K}$, and Prasad M, Patterns of diversity, abundance and habitat associations of butterfly communities in heterogeneous landscapes of the department of atomic energy (DAE) campus at Kalpakkam, South India. International Journal of Biodiversity and Conservation 2 (1) pp75-85,2010..

[23] Rickets TH,. Countryside biogeography of moths in a fragmented landscape: biodiversity in native and agricultural habitats. Conservation Biology 15(1)pp 378-388(2001).

[24] Rosin ZM, Myczko L, Piotr S, Lenda M, Moron D, Sparks TH and Tryjanowski P, Butterfly responses to environmental factors in fragmented calcareous grassland. Journal of Insect Conservation 16 (1) pp 321-329,2012.

[25]Rundlof, M. and Smith, H.G,. The effect of organic farming on butterfly diversity depends on landscape context. J. Appl. Ecol., 43(6): 1121-1127, 2006.

[26]Ruszczyk A and De Araujo ARE, Gradients in butterfly species diversity in an urban area in Brazil. Journal of Lepidopterists Society 46 255-264,1992.

[27] Saikia MK, Kalita J and Saikia PK, Ecology and conservation needs of nymphalid butterflies in disturbed tropical forest of Eastern Himalayan biodiversity hotspot, Assam, India. International Journal of Biodiversity Conservation 1(1) pp 231250,2009.

[28] Senthilkumar N, Biodiversity studies of Tettigoniids of Tamil Nadu and bio ecological characteristics of cynocephalus maculates. $\mathrm{PhD}$, Thesis submitted to University of Madras, Chennai, Tamil Nadu, India,2003.

[29] Shannon CE, A mathematical theory of communication. Bell System Technical Journal 27 379-423 and 623-656,1948.

[30] Sørensen TA, A method of establishing groups of equal amplitude in plant sociology based on similarity of species content, and its application to analyses of the vegetation on Danish commons. Kongelige Danske Videnskabernes Selskabs Biologiske Skrifter 5 1-34,1948.

[31] Soubadra DM, Priya D, Response of wet forest butterflies to selective logging in KalakadMundanthurai Tiger Reserve: Implications for conservation. Curr. Sci. India 80(3): 400-405, 2001.

[32] Southwood TRE, Ecological Methods with Particular Reference to the Study of Insect Populations. Chapman and Hall, London. pp:524,1978 .

[33] Sreekumar PG, Balakrishnan M, Habitat and altitude preferences of butterflies in Aralam Wildlife Sanctuary, Kerala, Trop.Ecol. 42(2): 277-281,2001. 
[34] Uniyal VP, Mathur PK, Diversity of butterflies in the great Himalayan National Park, Western Himalaya. Indian Journal of Forestry; 21(2):150155,1998 .

[35] Vandermeer, J. and Perfecto, I, Breakfast of biodiversity: the truth about rainforest destruction. Food First Books, Oakland, pp.185,1995.
[36] Youngberg, E.G., Parr. J.G. and Papendick, R.I,. Potential benefits of organic farming practices for wildlife and natural resources. Trans. North Am. Wildlife Nat. Res. Conf., 49: 141-153,1984.

Table.1:Fertilizer/Manures/Bio-pesticides/Insecticide application in conventional and organic fields

\begin{tabular}{|c|c|}
\hline Types of crops & Fertilizer/Manures/Bio-pesticides/Insecticide application in fields \\
\hline \multicolumn{2}{|r|}{ Conventional fields/hectare } \\
\hline Broad beans & $\begin{array}{l}100-115 \mathrm{~kg} \mathrm{~N} \text { (Urea) } \\
60-75 \mathrm{~kg} \mathrm{P}_{2} \mathrm{O}_{5} \text { ( Superphosphate) } \\
35-45 \mathrm{~kg} \mathrm{~K}_{2} \mathrm{O}(\mathrm{KCl}) \\
\text { 220-230 } 1 \text { Insecticides /ha } \\
\text { Artificial growth regulators }\end{array}$ \\
\hline \multicolumn{2}{|r|}{ Organic fields/hectare } \\
\hline Tomato & $\begin{array}{l}50 \mathrm{mg} \text { Cow dung compost } \\
13 \mathrm{mg} \text { Green manure } \\
1.5 \mathrm{mg} \text { Vermicompost } \\
501 \text { Panchakavya } \\
601 \text { Bio-pesticides } \\
\text { Neem seed kernel and neem leaf extracts } \\
\text { Farm yard manure }\end{array}$ \\
\hline
\end{tabular}

Table.2: Total number of butterfly species observed in conventional field in Bommanampalayam

\begin{tabular}{|c|c|c|c|c|c|c|}
\hline Temperature & $\begin{array}{l}\text { Start } \\
\text { time }\end{array}$ & End time & $\begin{array}{l}\text { Point } \\
\text { ID }\end{array}$ & Distance & Species Id & $\begin{array}{l}\text { No. of } \\
\text { Individuals }\end{array}$ \\
\hline $28^{\circ} \mathrm{C}$ & $16: 30$ & $16: 35$ & 1 & $50 \mathrm{~m}$ & Lampides boeticus & 5 \\
\hline $28^{\circ} \mathrm{C}$ & $16: 36$ & $16: 41$ & 2 & $50 \mathrm{~m}$ & Lampides boeticus & 4 \\
\hline $28^{\circ} \mathrm{C}$ & $16: 42$ & $16: 48$ & 3 & $50 \mathrm{~m}$ & Lampides boeticus & 8 \\
\hline $28^{\circ} \mathrm{C}$ & $16: 49$ & $16: 54$ & 4 & $50 \mathrm{~m}$ & Lampides boeticus & 11 \\
\hline $28^{\circ} \mathrm{C}$ & $16: 55$ & $17: 00$ & 5 & $50 \mathrm{~m}$ & Lampides boeticus & 7 \\
\hline
\end{tabular}

Table .3: Total number of butterfly species observed in organic field in Alandurai

\begin{tabular}{|c|l|l|l|l|l|c|}
\hline Temperature & $\begin{array}{l}\text { Start } \\
\text { time }\end{array}$ & $\begin{array}{l}\text { End } \\
\text { time }\end{array}$ & $\begin{array}{l}\text { Point } \\
\text { ID }\end{array}$ & Distance & Species Id & $\begin{array}{c}\text { No. of } \\
\text { Individuals }\end{array}$ \\
\hline $32^{\circ} \mathrm{C}$ & $16: 30$ & 1635 & 1 & $50 \mathrm{~m}$ & Castalias rosimon & 12 \\
\hline $32^{\circ} \mathrm{C}$ & $16: 37$ & 1642 & 2 & $50 \mathrm{~m}$ & Castalias rosimon & 9 \\
\hline $32^{\circ} \mathrm{C}$ & $16: 43$ & 1648 & 3 & $50 \mathrm{~m}$ & Castalias rosimon & 15 \\
\hline $32^{\circ} \mathrm{C}$ & $16: 50$ & 1655 & 4 & $50 \mathrm{~m}$ & Castalias rosimon & 11 \\
\hline $32^{\circ} \mathrm{C}$ & 1656 & 1701 & 5 & $50 \mathrm{~m}$ & Castalias rosimon & 14 \\
\hline
\end{tabular}


Table.4: Percent contribution of relative number of individuals and species of different families of butterflies recorded from the study areas

\begin{tabular}{|c|c|c|c|}
\hline Type of field & Family & $\begin{array}{c}\text { Total no. of } \\
\text { species }\end{array}$ & $\begin{array}{c}\text { Total no. of } \\
\text { individuals }\end{array}$ \\
\hline $\begin{array}{c}\text { Conventional } \\
\text { field }\end{array}$ & Lycaenidae & 1 & 35 \\
\hline Organic field & Lycaenidae & 1 & 61 \\
\hline
\end{tabular}

Table.5: Species richness, abundance and diversity of butterfly fauna sampled in two different fields in Coimbatore

\begin{tabular}{|c|c|c|}
\hline Ecological Indices & Conventional field & Organic field \\
\hline Simpson Diversity Index (D) & 0.13 & 0.40 \\
\hline Shannon-Wiener Diversity Index (H) & -0.16 & -0.12 \\
\hline
\end{tabular}

Plates
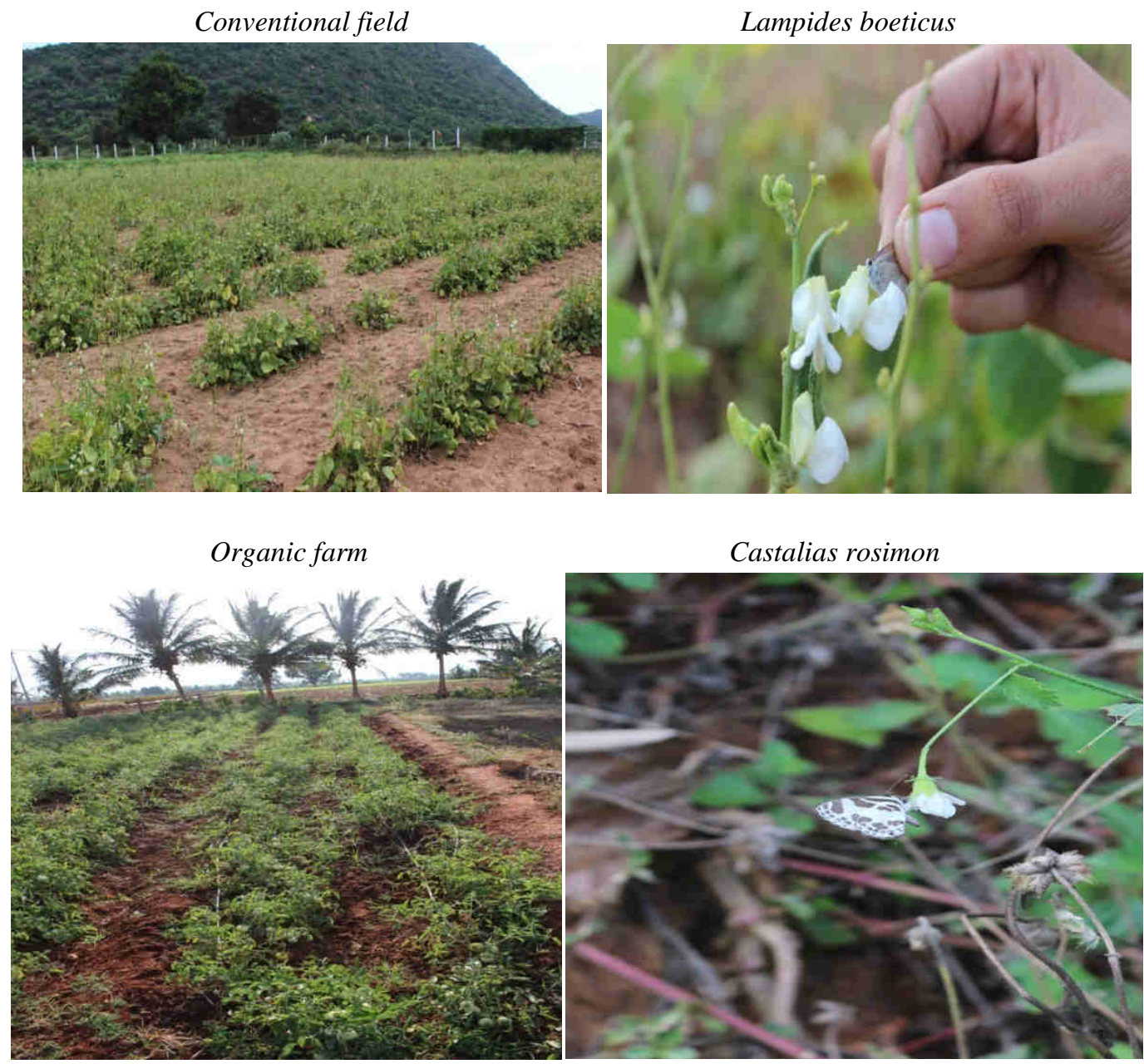